
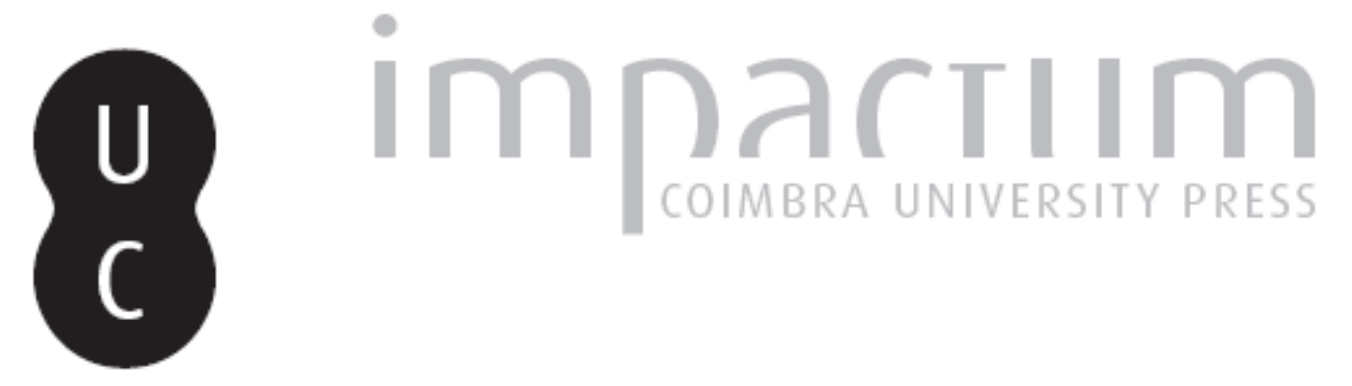

\title{
[Recensão a] Maria Bochicchio, O paradigma do pudor
}

\author{
Autor(es): Saraiva, Arnaldo
}

Publicado por: Imprensa da Universidade de Coimbra

URL persistente:

URl:http://hdl.handle.net/10316.2/42588

DOI:

DOI:https://doi.org/10.14195/0870-8584_4_17

Accessed : $\quad$ 26-Apr-2023 06:43:48

A navegação consulta e descarregamento dos títulos inseridos nas Bibliotecas Digitais UC Digitalis, UC Pombalina e UC Impactum, pressupõem a aceitação plena e sem reservas dos Termos e Condições de Uso destas Bibliotecas Digitais, disponíveis em https://digitalis.uc.pt/pt-pt/termos.

Conforme exposto nos referidos Termos e Condições de Uso, o descarregamento de títulos de acesso restrito requer uma licença válida de autorização devendo o utilizador aceder ao(s) documento(s) a partir de um endereço de IP da instituição detentora da supramencionada licença.

Ao utilizador é apenas permitido o descarregamento para uso pessoal, pelo que o emprego do(s) título(s) descarregado(s) para outro fim, designadamente comercial, carece de autorização do respetivo autor ou editor da obra.

Na medida em que todas as obras da UC Digitalis se encontram protegidas pelo Código do Direito de Autor e Direitos Conexos e demais legislação aplicável, toda a cópia, parcial ou total, deste documento, nos casos em que é legalmente admitida, deverá conter ou fazer-se acompanhar por este aviso.

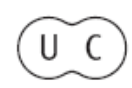




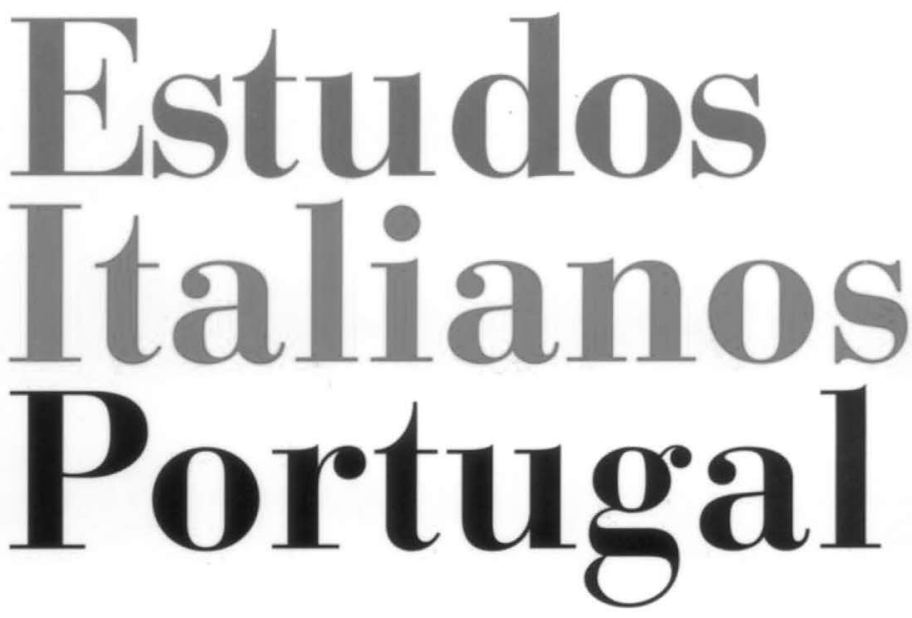

Instituto

Italiano

de Cultura

de Lisboa

Nova Série

$\mathbf{N}^{\mathbf{0}} 4$.

2009 
relação entre público e privado, a difusão de modelos e gostos.

O aproveitamento político da cultura e da arte volta a ser objecto de estudo no ensaio de Maria José de Lancastre, "Cronaca di un congresso (a proposito del quinto congresso internazionale della critica svoltosi a Lisbona nel 1931”) - pp. 39-49. Mais do que ligações luso-italianas, avulta aqui um mapa europeu, e o congresso dos críticos europeus, organizado por António Ferro nos primeiros anos do Estado Novo, é avaliado pela autora como uma manobra de sedução que acreditou no préstimo da cultura como trunfo maior. Numa altura em que se pretendia debater o ascendente dos críticos e as formas do exercício da crítica, o encontro de 1931 - afirma a autora - veio ilustrar essa influência: o zelo propagandístico de António Ferro revelava esperança no vasto alcance público e, eventualmente, no fundo impacto do discurso dos críticos; o teor das críticas recenseadas por Maria José de Lancastre mostra quão certeira foi essa convicção.

Traduzioni, imitazioni, scambi tra Italia e Portogallo nei secoli tes- temunha a riqueza deste campo de pesquisa. Garantem Davide Conrieri e Valeria Tocco "proseguire su questa via” (p. VIII), e o leitor do presente volume não hesitará em formular um voto benigno: assim seja! ISABEL ALMEIDA

\section{Maria Bochicchio, O paradigma} do pudor, Vila Nova de Famalicão, Edições Quasi, 2007, pp. 279

A pátria portuguesa é às vezes ingrata para com os seus filhos; mas mais ingrata é, como regra, para com os estrangeiros que a privilegiaram, ou que dão provas de lusofilia, os quais, se podem dever-lhe algum apoio pontual, ou alguma bolsa, não têm incentivos regulares ou o apoio e o reconhecimento público - nem que fosse traduzido em convites, condecorações, prémios, e até em verbetes de dicionários - que merecem a sua dedicação à cultura portuguesa e as suas contribuições para o seu conhecimento e divulgação.

Vivendo em países próximos ou longínquos, indo e vindo ou fixando-se entre nós, como se fixaram a alemã Carolina Michaëlis ou o sardo Michel Giacometti, 
não são poucos os que produziram obras que nos enriquecem, e que nalguns casos até nos ensinam a descobrir e a valorizar o que temos. Aos dois nomes referidos poderíamos associar muitos outros, antigos como o italiano Nasoni ou o inglês Barão de Forrester, e modernos como o inglês Charles Boxer, o italiano Antonio Tabucchi, o espanhol Angel Crespo, o francês Frédéric Mauro, o norte-americano Arthur Askins, o alemão Curt Meyer-Clason por exemplo.

Há lusófilos de muitas nacionalidades; mas depois dos brasileiros são os italianos que mais têm trabalhado - desde os tempos dos cancioneiros Colocci-Brancuti e da Vaticana - em favor da cultura portuguesa; para o provar, bastaria que nos reportássemos ao século XX, e lembrássemos apenas os nomes dos já falecidos Giuseppe Carlo Rossi, Silvio Pellegrini, Gino Saviotti, Guido Battelli, Vincenzo Spinelli, Leo Magnino, Giacinto Manuppella, Luciana Stegagno Picchio, Carlo V. Cattaneo... Actualmente, impressiona o número de investigadores, críticos, tradutores, professores e criadores italianos - alguns dos quais já tão prestigiados como Giuseppe Tavani, ou como Ettore Finazzi-Agrò - dedicados à causa da literatura portuguesa. A eles acaba de se juntar Maria Bochicchio, que, em colaborações dispersas mas sobretudo em $O$ paradigma do pudor dá conta não só dos seus largos conhecimentos sobre José Régio e sobre a poesia portuguesa moderna, mas também de uma sólida formação teórico-crítica, com especial relevância na área dos estudos textuais, ou ecdóticos, ou crítico-genéticos, que propõem a melhor lição do texto, denunciando gralhas, censuras, supostas correcções ou revisões à revelia do autor, e que esclarecem a sua génese, as hesitações, os avanços, os recuos, os saltos que conduzem ao texto autoral final.

Maria Bochicchio não esconde a sua dívida ("este trabalho inspira-se no modelo"...) em relação à teoria e à prática internacionalmente reconhecida de Giuseppe Tavani, que aliás prefacia, juntamente com o especialista regiano Eugénio Lisboa, o seu livro, e o considera "um óptimo exemplo de edição crítico-genética". Mas ela não desconhece outras teorias e não 
podia ser indiferente aos exemplos de numerosos filólogos italianos - que constituem uma informal mas verdadeira "escola" ao serviço de Portugal - a quem se devem estudos textuais e edições críticas de autores portugueses, sobretudo medievais: lembremos, entre outros, além dos já citados Tavani, Luciana, Ettore, os nomes de Valeria Bertolucci-Pizzorusso, Fernanda Toriello, Giulia Lanciani, Anna Ferrari, Maurizio Perugi, Barbara Spaggiari...

Integrando-se com brio nessa brilhante tradição, Maria Bochicchio optou porém pela edição crítica de uma obra relativamente recente, publicada pela primeira vez em 1954 - $A$ chaga do lado, de José Régio.Tal escolha vale desde logo como um desafio (e uma adequada e definitiva resposta) a quantos julgam equivocada ou "imprópria” a "aplicação da crítica textual às obras literárias modernas e contemporâneas"; mas tem também o mérito de contemplar uma obra "importante do cânone regiano" (Eugénio Lisboa), uma obra singular e pouco estudada de um Régio já cinquentenário, ou uma das obras poéticas mais veementes e pro- vocatórias da poesia portuguesa das últimas décadas. E não se pense que Maria Bochicchio faz apenas o que diz em subtítulo, a "edição crítico-genética" desse livro; o enigmático ou metafórico título O paradigma do pudor talvez deixe de parecer impertinente quando se lê a primeira parte, onde são cuidadosamente analisadas questões centrais da obra de Régio em geral e em especial de $A$ chaga do lado: o inconformismo social e espiritual, o confessionalismo e as suas ficções, a inquietação religiosa, a exigência da verdade.

Com brevidade, mas também com grande rigor, Maria Bochicchio reflecte sobre o percurso humano e poético de José Régio antes do e durante o período da produção dos poemas de $A$ chaga do lado, assinalando o que num e noutro desses percursos dá conta da "busca da perfeição". Mas na segunda parte do livro, no estudo e nas notas que acompanham a edição da obra regiana, a estudiosa italiana exibe mais do que a sua gula de leitora - que, diz Eugénio Lisboa, "se não leu tudo, leu quase $t u d o$ " - e a sua boa formação de ensaísta e de biógrafa ou de historiadora literária, pois 
dá sobejas provas das suas capacidades de filóloga e de investigadora, que tentou juntar e explicar todos os materiais pré-textuais e para-textuais ("autógrafos, ideógrafos, provas de impressão", "diários, correspondência, biografias, etc.”), não desprezando nenhum "testemunho", exibindo até 23 facsímiles de inéditos, e detendo-se depois na análise minuciosa das variantes.

O escrúpulo da estudiosa que andou por espólios, bibliotecas, entrevistas, e que valorizou rascunhos, borrões, provas, fragmentos, vê-se também nas anotações minuciosas e no esforço para apresentar e sinalizar o texto regiano e as suas variantes com a máxima clareza, num bonito modelo e aparato gráfico que definiu por certo em diálogo com os responsáveis das Edições Quasi.

No final, não será dificil ao leitor acompanhar as conclusões de Maria Bochicchio sobre a "psicologia da composição” de Régio, sobre a tipologia das suas variantes, sobre as suas opções estético-literárias. Mas também não será difícil ao leitor reconhecer os muitos méritos desta nova lusófila italiana. Régio confessou um dia “a um jovem poeta": ”Já te dei tudo quanto posso". Maria Bochicchio despendeu neste seu fecundo e modelar trabalho muita energia investigadora e analítica; por ele intuímos que ela tem ainda muito e muito valioso a dar não só a Régio mas também à poesia, à cultura e à língua portuguesa que tanto ama - e que desde já lhe deve estar reconhecida. ARNALDO SARAIVA

\section{Futurismo Avanguardia Avanguar-} die, a cura di Didier Ottinger, $\mathrm{Pa}-$ rigi, Centre Georges Pompidou, Milano, 5 Continents Éditions, 2009, 359 pp.

\section{Futurismo 1909-2009 Velocità +} Arte + Azione, a cura di Giovanni Lista e Ada Masoero, Milano, Skira, 2009, 451 pp. + CD

Se o lastro e a memória de uma exposição perduram através das páginas do seu catálogo, boa parte da mais recente história crítica sobre o Futurismo, nas suas valências europeias e internacionais, está ligada à concepção de uma célebre mostra, que remonta a 1986, e cujo catálogo constitui uma referência para os estudiosos da matéria. Refiro-me a $\mathrm{Fu}$ turismo e Futurismi. Catalogo della mostra, Venezia, Palazzo Grassi 